\title{
The Methodology and Research Participation Experiences of Participants in the Aborted Suicide Attempt Study
}

\author{
Paul W. C. Wong1,2*, Noel C. F. Kwok, Konrad Michel ${ }^{3}$, Gilbert K. H. Wong4 \\ ${ }^{1}$ The Department of Social Work and Social Administration, The University of Hong Kong, Hong Kong, China \\ ${ }^{2}$ The Hong Kong Police College, The Hong Kong Police Force, Admiralty, Hong Kong, China \\ ${ }^{3}$ University Hospital for Psychiatry, University of Bern, Bern, Switzerland \\ ${ }^{4}$ The Police Negotiation Cadre, The Hong Kong Police Force, Admiralty, Hong Kong, China \\ Email: *paulw@hku.hk
}

How to cite this paper: Wong, P. W. C., Kwok, N. C. F., Michel, K., \& Wong, G. K. H. (2017). The Methodology and Research Participation Experiences of Participants in the Aborted Suicide Attempt Study. Psychology, 8, 59-76.

http://dx.doi.org/10.4236/psych.2017.81005

Received: December 12, 2016

Accepted: January 9, 2017

Published: January 12, 2017

Copyright (c) 2017 by authors and Scientific Research Publishing Inc. This work is licensed under the Creative Commons Attribution International License (CC BY 4.0).

http://creativecommons.org/licenses/by/4.0/

\begin{abstract}
The participants' study participation experiences in an intensive research methodology that examined recent aborted suicide attempts were explored. Individuals aged 18 or above and whose suicide attempts were voluntarily aborted after the suicide crisis negotiation with the police negotiators were interviewed and followed up at 1 and 3 months after the initial interview. Eleven participants gave their consent to the Police Negotiation Cadre of the Hong Kong Police Force for further contact by the research team during June 2012 and December 2014. Nine aborted attempters completed the semi-structured interviews conducted by the research team about their suicide attempt processes and the events leading to that. Seven of them completed the 3 months follow up. The majority of the participants were positive about being approached to take part in the study. They found the experience of talking about their suicide attempts more positive than expected, and felt the study participation was useful for them and meaningful for the society. None of the participants reported being distressed by the recruitment method or the interviews. Results suggest that such sensitive non-treatment research when conducted ethically, participants could benefit from it.
\end{abstract}

\section{Keywords}

Sensitive Research, Aborted Suicide Attempt, Research Participation Experience, Hong Kong, Suicide Crisis Negotiation 


\section{Introduction}

The prevention of suicide attempt is a key strategy to reduce the possible suicide because previous suicidal behavior is one of the most robust predictors of future re-attempts and suicide (Kessler, Berglund, Borges, Nock, \& Wang, 2005). It is estimated that individuals with a history of suicide attempts were about 40 times more likely to suicide than those who had not attempted suicide (Moscicki, Muehrer, \& Potter, 1995). (Owens, Horrocks, \& House, 2002)'s systematic review of 90 studies on self-harm found that subsequent suicide and non-fatal repetition occurs in somewhere between 1 in 200 and 1 in 40 self-harm patients in the first year of follow-up, respectively.

Suicidal behavior is a complex and heterogeneous phenomenon (Nock et al., 2008). Many nomenclatures for the classification of suicidal behaviors (Brown, Jeglic, Henriques, \& Beck, 2006; Silverman, Berman, Sanddal, O'Carroll, \& Joiner, 2007) generally propose that suicidal behaviors range from risk-taking thoughts and behaviors, suicide-related thoughts, and suicide threats, to suicide attempts and completed suicides (Marzuk et al., 1997) and identified that individuals who had the intent to complete suicide, but changed their minds immediately before the actual attempt and without any injury occurring could be defined as aborted suicide attempt. In the 2012 Draft Guidance on assessing 11 categories of suicidal behaviors in drug trials issued by the United States Food and Drug Administration (The Division of Psychiatry Products in the Center for Drug Evaluation and Research (CDER) at the Food and Drug Administration, 2012) based on the Columbia-Suicide Severity Rating Scale (C-SSRS) (Posner et al., 2008; Posner et al., 2011), aborted suicide attempt was one of the categories of the spectrum of suicidal ideation and suicidal behavior that to be documented in clinical trials. According to the 733 (Marzuk et al., 1997), 135 (Barber et al., 1998), and 400 (Ghaffari-Nejad \& Pouya, 2002) semi-structured interviews on the history of aborted suicide attempt with psychiatric inpatients in the United States and Iran, some patients used the aborted attempts as rehearsals for more lethal suicidal behavior. They were also much more likely to make an actual attempt in the future. Studying aborted suicide attempt has an exclusive opportunity for examining what thoughts and actions had taken place in the suicidal individuals to make them detour from their suicidal plans. However, besides the studies by Marzuk et al. (1997), Barber et al. (1998), and Ghaffari-Nejad and Pouya (2002), as far as we know, there are no studies in which researchers have collected information from aborted suicide attempters immediately after their aborted attempts. Such information with minimal recall bias is much needed given the actual reasons and psychological processes, and negotiation processes that led to the aborted suicide attempts remain largely unexplored.

Hong Kong provides a rather unique opportunity to study aborted suicide attempts. In particular, jumping from a height is the most common suicide method in this city. Between 1981 and 2010, about half (49.7\%) of the total 23,995 suicides consisted of jumping from a height; about $83 \%$ of these suicide jumps occurred from residential buildings, and of these, $61 \%$ occurred from the dece- 
dents' own residences (Wong, Caine, Lee, Beautrais, \& Yip, 2014). Roughly seven million residents, in other words, over $90 \%$ of the people in this region live in multi-story buildings. Hence, when a person chooses to die by suicide through jumping from a height in Hong Kong, he or she is more likely to climb out of a window from his or her own residency or go to the roof of the building. Moreover, suicide by jumping from a height in Hong Kong is easier to be noticed by others and reported by witnesses to the law enforcement agency for rescue attempts considering physical distances between buildings are relatively small. Using the unique suicide milieu in Hong Kong, we conducted a case series study in collaboration with the Police Negotiation Cadre (PNC) of the Hong Kong Police to investigate the aborted suicide attempt process both through the aborted attempters' and negotiators' perspectives.

Ethical issues may arise if the research methodology was not carefully planned and/or implemented (Mishara \& Weisstub, 2005). We acknowledge that emerging evidence has shown that most study participants in research in sensitive areas like, trauma and bereavement, did not have increased distress after study participation (Smith, Poindexter, \& Cukrowicz, 2010). For instance, Lakeman and Fitz Gerald (2009) conducted a survey of Institutional Review Board (IRB) committee members' ethical concerns regarding the conduct of suicide research. They found that about $65 \%$ of respondents believed participation in suicide research could be detrimental to the participants. In particular, the survey participants in their study believed that suicidal symptoms may intensify about the discussion on their own suicidal tendencies (Lakeman \& FitzGerald, 2009). Therefore, this study involved recruiting and interviewing vulnerable and highrisk individuals who aborted their suicide attempts after negotiations with the PNC. Nevertheless, we are cautious about the potential unintended harm that our study may bring to the study participants. Hence, we evaluated the effect of participating in our research study on aborted suicide attempt that inquired extensively about the recent suicidal plans and negotiation processes with the police offices during the attempts.

There are two parts to this article. In the first part, we describe the methods of recruitment and data collection of our study. In the second part, we describe the follow-up study findings of the participants' reactions to study participation and the impact of the interviews on participants during and after the intensive interviews. The major aims of the follow-up study were: (1) to investigate whether the aborted suicide attempters recruited through the police negotiators found it appropriate as a study recruitment strategy; (2) to investigate the impacts of the interviews on the study participants about a month and three months (Smith et al., 2010) and one year after the interviews; and (3) to explore the reactions and reasons for participation of the interviews. Such information is needed because they provide an empirical measure of the ethical acceptability of our study approach. We hypothesized that, when ethical issues were carefully considered and appropriate measures were prepared and implemented, the participants in this sensitive research would not react with an increase of suicidal ideation or behaviors more than would be expected by chance at the time of follow-up. 


\section{Method}

\subsection{Recruitment of the Participants through the Police Negotiation Cadre (PNC)}

To ensure that the recruitment method was ethical which created as little as possible to the disturbance to the normal operation of the PNC, we conducted two in-depth discussions with the 10 team leaders of the PNC in August 2011 and March 2012. In the first session, the research team introduced the objectives, the proposed methodology for recruitment of participants through the Hong Kong Police, and discussed the potential obstacles with the PNC team leaders. In the second discussion, after consultation with the team members of PNC, the team leaders reported the foreseeable difficulties of the recruitment process (e.g., the appropriateness of introducing the research when the subject was emotionally unstable after the negotiation). We, therefore, collaboratively generated the inclusion and exclusion criteria with the PNC to ensure the methodology was ethically and practically appropriate. The research team and the PNC proposed that a turn-out record form should be developed for this study to monitor the progress and potential adverse events during the study. Hence, the record form included the date of the incident, profile of the subjects, nature of the incident, handling team, resolution of the incidents, duration of negotiation, primary reasons for the attempt, and the presence of suicide notes was developed by the PNC and the form was completed immediately after every turn-out by the PNC. The PNC would then pass the data to the research team bimonthly for recruitment process monitoring. We piloted the recruitment method in June 2012 and we started the data collection in August 2012.

We conducted a training session in collaboration with the Psychological Service Group of the Hong Kong Police Force for all PNC members in October 2012 after the research team successfully recruited and interviewed two aborted suicide attempt cases between August and October 2012. The aim of the training session was to enhance the understanding of the PNC members of how we collected the research data and what research data we collected once they had referred the potential participants to the research team and also as a team-building exercise between the research team and the PNC.

\subsection{Participants}

In this study, we only recruited suicide attempters who had been engaged by the police negotiators and who had aborted their attempts after crisis negotiation. The inclusion criteria were: (i) subjects who were at least 18years of age, (ii) who were Cantonese speaking, and (iii) who voluntarily aborted their suicide attempts after the negotiation with the PNC. The participants were excluded if (i) the other police officers or fire officers had forcefully interrupted and aborted their suicide attempts, (ii) they were involved with criminal cases that may lead to subsequent prosecution, and (iii) suffered from known schizophrenia spectrum and other psychotic disorders. 
After the negotiation, a police negotiator at the scene gave the aborted attempters an introductory letter about the study and a manual on managing selfharm (http://csrp.hku.hk/wp-content/uploads/2015/06/guide_dsh.pdf) before the attempters were escorted by the ambulance to the closest hospitals for medical assessment and treatment. A police negotiator then sought written consent from the aborted attempters for forwarding the name and contact details to the research team. If consented, a PNC member would pass a copy of the written consent to the research team within two working days. The research team then contacted the consented aborted attempters for study participation and interviews through a telephone call and invited the participants for interviews within one to two weeks after the negotiation at a convenience place suggested by the consented participants.

\subsection{The Narrative and Semi-Structured Interviews}

The face-to-face interview comprised a narrative interview part and a semistructured interview part. The interviews were audio-or/and video-taped with the participants' written consent. Having signed a consent form, the research team first asked the participants to talk about their experiences about aborted suicide attempts in chronological order, starting with statements or questions such as "I would like you to tell me in your own words", "I would like to hear the story behind your suicide attempt" (Michel, Dey, Stadler, \& Valach, 2004), or "So how is your life now after the aborted attempt?".

Once each participant had completed the narrative interview, the research team then used the semi-structured interview to explore any relevant issues that had not already emerged. We classified the examined themes of the semi-structured interview part into four broad domains: (I) socio-demographic characteristics, (II) clinical factors, (III) life events, and (IV) psychological and cognitive factors. The themes were considered and generated based on the constructs of the stress-diathesis theory (Traskman-Bendz \& Mann, 2000) and the suicidal process model (Van Heeringen, Hawton, \& Williams, 2000). In brief, according to the stress-diathesis model, suicidal behavior is associated with multiple risk factors, and the behavior has been conceptualized as the outcome of the interaction between an individual's diathesis for suicidal acts and triggers for suicidal behavior. The diathesis refers to the propensity for manifesting suicidal behavior and may be considered trait-related and independent of psychiatric diagnosis. In contrast, triggers are precipitants or stressors that determine the timing and probability of suicidal acts. Thus, triggers may be considered state-related. This model helps to explain why when an individual encounters a stressor, he/she would commit suicide while another would not (Traskman-Bendz \& Mann, 2000). The suicidal process model also consider suicidal behavior as a multifaceted issue and the conception of the suicidal process implies that age of onset is earlier and less severe for death wishes and later and more serious for suicide attempts but the process fluctuates and depends on the cultural context. At the end of the interviews, all participants received HKD300 (about USD40) to com- 
pensate for their time or travelling costs.

\subsection{Measures}

Socio-demographic characteristics. The socio-demographic characteristics that we investigated included marital status, educational status, ethnicity, living arrangement, employment status, and income.

Clinical factors. The clinical factors that we investigated included the presence of a diagnosed psychiatric disorders, except psychotic disorders, at the time of the interview, a history of psychiatric disorders, previous psychiatric treatment, previous suicide attempts using the Chinese version of the Beck Suicide Intent Scale (Zhang \& Jia, 2007), and the Reasons for Attempting Suicide Questionaire (Holden \& McLeod, 2000).

Life events. We investigated culturally specific adverse life event variables including relationship, family, work, physical health, and legal issues using a list that had been used in a previous psychological autopsy study (Chen et al., 2006; Wong et al., 2008).

Psychological and cognitive factors. The research team used the Social Problem-Solving Inventory (D'Zurilla \& Nezu, 1990), the Multidimensional Scale of Perceived Social Support (Zimet, Powell, Farley, Werkman, \& Berkoff, 1990), the Zimbardo Time Perspective Inventory (Sircova et al., 2014), the Reasons for Living Inventory (Linehan, Goodstein, Nielsen, \& Chiles, 1983), Family Problem-Solving Communication (McCubbin, McCubbin, \& Thompson, 1996), the General Health Questionnaire (Goldberg \& Williams, 1988), and the Meaning in Life Questionnaire (Steger, Frazier, Oishi, \& Kaler, 2006) to measure the most relevant psychological and cognitive constructs in the participants.

\subsection{The Follow-Up Interviews}

We conducted the follow-up telephone interviews for one month and three months after the initial interviews. We also conducted a face-to-face interview for one year after the initial interviews. Through the follow-up interviews, we aimed to identify the presence of further risk for attempting suicide. Example questions were as follows: "Do you have a wish to die now?", "Have you thought of killing yourself recently?". We also aimed to explore the participants' emotional responses and comments after participating in the study because of ethical concerns for our participants a possibility of being distressed by the interviews. We based the items asked in the telephone interviews about participants' experiences of participating in the study on a questionnaire developed by (Hawton, Houston, Malmbergand, \& Simkin, 2003) in the United Kingdom, which Wong et al. (2010) adopted and modified in their previous psychological autopsy study.

The items included 15 close-ended questions graded by three categories (i.e., yes, no, or no comment) that asked about the informants' reactions to the method of initial contact regarding participating in the study, the informants' feelings during and within a month after the interviews, and whether the informants regretted participation. In addition, the research team asked two open-ended 
questions about the informants' reasons for participation and their overall comments and recommendations for future studies. At the end of the interview, the research team thanked the subjects for their participation and offered further contact or help if required. We also conducted the face-to-face follow-up interview about one year after the initial interview. The interview was unstructured and the main aim was to explore the recovery process of the participants.

\subsection{Risk Management}

Due to the sensitive nature of the research, a robust risk management procedure was developed for the project. In particular, the mobile and office contact numbers of the interviewers were provided to the participants immediate after the interviews. Participants were encouraged to contact the research team should they wish to before their next consultations with the social workers. The research team also searched and printed the contacts of the closest social services centers for the crisis management purpose and passed them to the participants after the interviews.

\subsection{Interviews with the Negotiators}

We conducted interviews with the police negotiators who were involved as soon as possible after the negotiations to minimize the recall bias. We adopted an unstructured format, and we asked the negotiators to describe the incidents that our study participants were involved in a chorological order starting with the question "Can you tell me what happened during the call-out from the time you received the call to the time the incident ended?". We also asked about any potential impact of the incidents on the negotiators. We asked the negotiators if the recruitment process had any adverse impacts on the potential participants. The Human Research Ethics Committee of The University of Hong Kong (EA 210211) approved this study.

\subsection{Data Analysis}

We used descriptive statistics to report the demographics of the participants. To ensure the reliability of the answers and comments to all open-ended questions, a bilingual research assistant (NCFK) translated them from Chinese to English in collaboration with another bilingual author (PWCW). A qualitative review and categorization of open-ended text responses were performed.

\section{Results}

From 1 June 2012 to 31 December 2014 (31 months), the PNC received a total of 241 cases. Among the 241 cases (see Figure 1), the PNC classified 231 as suicide attempt cases. Out of all the cases, the PNC intervened in 122 call-outs, which included 118 suicide attempt cases. Eighty one cases aborted their attempts after negotiations with the PNC, the other police officers or fire officers forcefully aborted 36 cases after the negotiations, and three cases completed suicide by jumping during the rescue. Among the 81 cases, we found the following as the 


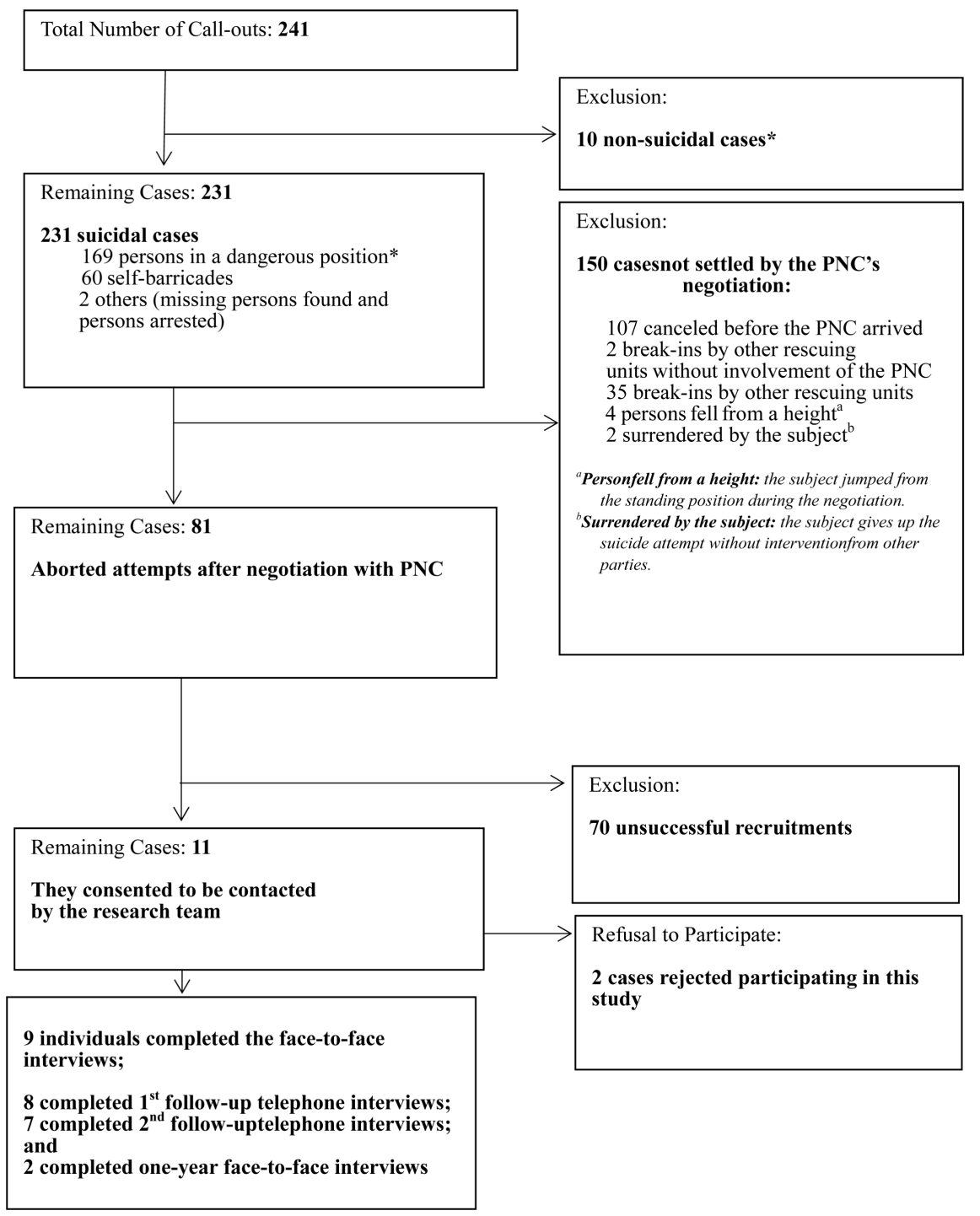

Figure 1. The recruitment flowchart.

principal reasons for their suicide attempts: emotional instability $(n=9,11.1 \%)$, intimate relationship problems $(\mathrm{n}=56,69 \%)$, work problems or financial problems $(n=35,43.2 \%)$, family issues, and/or health problems $(n=22,27.2 \%)$.

\subsection{Characteristics of Participants}

Among the 81 aborted suicide attempt cases, 11 cases consented to the PNC for being contacted by the research team and matched with the inclusion criteria of the study to warrant further contact by the research team. However, two cases refused to participate after their initial phone contact with the research team. Hence, the research team interviewed nine aborted suicide attempters. Seven of them planned to attempt suicide by jumping from a height, one by wrist cutting and poisoning by gas simultaneously, and one by throat cutting. The mean duration of the negotiations was about 123 minutes. Figure 1 shows the flow of the recruitment and interview processes. 
Among the nine cases, two (22.2\%) were females and four (44.4\%) were aged between 40 and 49 years old-the youngest was 24 and the oldest was 79 . Five participants (55.6\%) reported a life-time history of suicide attempt, four $(44.4 \%)$ had a 12-month history of self-harm, and one (11.1\%) had a 12-month history of suicide attempt. Six participants $(66.7 \%)$ were married, five (55.6\%) were in debt, and seven $(77.8 \%)$ were employed or self-employed. The research team carried out the interviews with the nine cases, on average, two-and-a-half weeks after the attempt incident because all of the participants were hospitalized after the attempts. The research team conducted seven of the interviews at the participants' residences and two in the office of PWCW. PWCW and NCFK conducted all interviews. The duration of the interviews was about 120 minutes. However, not all of the cases could participate in the follow-up interviews. The research team conducted eight one-month and seven three-month telephone follow-up interviews and only two one-year face-to-face follow-up interviews. The main reasons for the low number of one-year follow-up interviews included refusal to be interviewed again $(n=4)$ and loss of contact $(n=3)$.

\subsection{Negotiators}

The research team interviewed 10 (two females) police negotiators who were involved in the crisis negotiations of the study participants. They completed nine interviews at the Police Headquarters of the Hong Kong Police Force and one interview at the officer's home. The mean duration of the interviews was about 73 minutes. None reported having any adverse events happened to neither the potential participants nor themselves during the recruitment.

\subsection{Participants' Reactions to the Study}

Table 1 shows the results of the follow-up interviews. After one month, only one individual had a moderate-to-strong-wish to die; after three months, no individuals had a wish to die; and no individuals had suicidal thoughts at the time of the three-month follow-up interview. Five and four cases did not expect to make another attempt at the time of the one-month and three-month follow-up interviews, respectively.

With regard to the participants' feelings toward the study, around $85 \%$ were positive about having been initially approached to participate in the study. However, probably because of the time involved in the face-to-face interviews, almost half of the participants at both follow-up suggested that telephone interviews were preferable to face-to-face interviews. All of the participants reported that the interviews had been a positive experience in both follow-ups and they had either a positive or neutral feeling in relation to having talked about their suicidal experiences. Furthermore, almost $85 \%$ reported to have felt better after the interviews, and 70 - 80 percent of them reported to finding themselves becoming more open to talk about the attempt with their significant others. No participants reported being regretful for study participation. It is noteworthy that it seems that participants were less willing to talk about their suicide 
Table 1. The responses of the informants of suicide and control cases when being contacted, and their immediate and subsequent reactions to psychological autopsy interviews.

Follow-up Telephone Interviews

One month later ${ }^{(a)} \quad$ Three months later ${ }^{(a)}$

Items

$$
(\mathrm{N}=8)
$$$$
(\mathrm{N}=7)
$$

Frequency

\section{A. Mental Health and Suicidality}

1. Do you have a wish to die?

I have no wish to die.

I have a weak wish to die.

I have a moderate-to-strong wish to die.

$\begin{array}{cccc}5 & 62.5 & 7 & 100.0 \\ 2 & 25.0 & 0 & 0.0 \\ 1 & 12.5 & 0 & 0.0\end{array}$

2. Have you thought of killing yourself recently?

I rarely or only occasionally think about killing myself.

I have frequent thoughts about killing myself.

I continuously think about killing myself.

$\begin{array}{llll}2 & 25.0 & 0 & 0.0\end{array}$

3. What is/are your primary reason(s) for attempting suicide?

Primarily aimed at influencing other people.

Not only aiming to influence other people, but also representing a way of solving my problems.

Primarily based upon escaping from my problems.

$0.0 \quad 0$

4. Do you expect to make another suicide attempt?

I do not expect to make a suicide attempt.

I am unsure whether I shall make a suicide attempt.

I am sure that I shall make a suicide attempt.

$\begin{array}{llll}3 & 37.5 & 2 & 28.6 \\ 3 & 37.5 & 2 & 28.6 \\ 2 & 25.0 & 3 & 42.9\end{array}$

\section{B. About Being Contacted}

5. How did you feel about being contacted?

Positive.

Neutral.

Negative.

6. How did you feel about receiving the face-to-face interview (would you have preferred a phone call or some other method of contact)?

Face-to-face interview.

Telephone.

7. Would you have preferred to have your contact method passed to us by someone else such as the police or a member of the Police Negotiation Cadre (PNC)?

Yes. 


\section{Continued}

\section{About the Interview(s)}

8. Did you find the interview upsetting?

No, it was rather a positive experience.

No, I didn’t.

$\begin{array}{cccc}7 & 87.5 & 7 & 100.0 \\ 1 & 12.5 & 0 & 0.0 \\ 0 & 0.0 & 0 & 0.0\end{array}$

Yes, (it made me) feel much sorrow.

9. How did you feel when talking about the suicide attempt?

Positive.

Neutral.

Negative.

$\begin{array}{llll}7 & 87.5 & 4 & 57.1 \\ 1 & 12.5 & 3 & 42.9 \\ 0 & 0.0 & 0 & 0.0\end{array}$

10. How did you feel after the interview?

Better than Before.

No Change.

Worse than Before.

$\begin{array}{llll}1 & 12.5 & 1 & 14.3\end{array}$

\section{Subsequent Reactions}

11. How do you feel now (one month and three months later)?

Better than before.

No change.

Worse than Before.

$\begin{array}{lll}0.0 & 0 & 0.0\end{array}$

12. Did the face-to-face interview help you to talk about the suicide attempt?

Yes.

I don't know.

13. Since the interview, have you found yourself becoming more willing to talk about the attempt with others (e.g., family, friends, and relatives)?

Yes.

No.

I don't know.

14. Do you regret your decision to take part (in the study)?

Yes.

No.

I don't know.

15. Do you think the time interval between the actual suicidal attempt and when you are contacted by us is appropriate? Would you prefer a longer time interval between the incident and when you are contacted by the research team?

Good Timing.

Prefer earlier contact.

Prefer later contact.

$\begin{array}{llll}0 & 0.0 & 0 & 0.0 \\ 7 & 87.5 & 6 & 85.7 \\ 1 & 12.5 & 1 & 14.3\end{array}$


attempts at the second follow-up and we could only interviewed two participants one-year later.

Table 2 shows the responses to the open-ended questions regarding the participants' reasons for participation and overall comments and recommendations. The two major themes for reasons of study participation were (1) hoping to help others and (2) to help oneself. The two major themes for comments to the study were (1) the study was helpful to them and (2) the study was meaningful to the society. The research team did not receive any negative comments about the study.

Table 2. Participants' comments to the open-ended questions.

\footnotetext{
Q1.What was the main reason(s) for you taking part in the research?

$>$ "I hoped more people would understand me so that they would know how bad and disgusting my husband was."

$>$ "I hoped it (participating in the research study) may help others."

$>$ "I believed that I would benefit from participating in the research."

"I hoped to understand others more. I treated this experience as a chance to obtain knowledge... moreover, I was curious to know whether I was different from the others taking part. I wondered what was forcing other people to want to move into the last stage of life as well."

$>$ "I wanted to share my problems with someone."

> "As a way to soothe myself and to gain experience."

"I believed that it would help more and more people."

$>$ "Not sure, just simply needing somebody else to share my thoughts and feelings with."

> "We ought to do whatever is beneficial to others. Therefore, I hoped I could do more for others. By the way, I believe there is room for improvement among the social workers and organizations. For instance, sometimes when I need help from the social workers during the weekend, this is rather upsetting when I am told that the social workers were not available on Saturdays and Sundays."

> "As a way to express my words in my mind, and to feel relieved about my negative feelings."

> "Good to have people to talk to when feeling bad."

> "I hoped it could help relieve myself from my mysteries, and I think this is a positive project."
}

Q2. Are there any other comments you would like to make about the way the study was carried out, the letters, or the questionnaire you received?

$>$ "There is no need to improve; it was good enough already."

$>$ "Better liaising with me or other participants in the hospital. This is because I was approached by a variety of organizations and it is hard to distinguish between them all."

> "Better to include more counseling services, which is very helpful to us."

$>$ "This research not only benefits others, but it also helped me too."

> "I really appreciate the positive work you all are doing."

> "No comment. It has been very good to have someone to talk to."

$>$ "Hopefully the messages can reach the organizations providing the community services so that they know how to improve."

> "You all are very good to me; you have helped me a lot. In the past, I have not been sure about what I can do with my problems. But now, I feel great relief because I can find someone with whom to share my sadness. It's a chance for me to reflect and to learn to be open-minded. I found hope from this research. I treated this experience as a way to make new friends."

"Good to have people to talk with and it helped me so much." 


\section{Discussion}

A number of local studies have investigated the profiles and risk factors of suicide attempts in hospital settings (Chan, Yip, Au, \& Lee, 2005; Chang et al., 2015; Yim et al., 2004) and among adolescents (Cheung et al., 2013; Law \& Shek, 2013; Lee et al., 2009; Wong, Stewart, \& Lam, 2007; Wong et al., 2008). Researchers have not often investigated the lived experiences of people in Hong Kong who have self-harmed, except for Chan et al. (2005)'s study, in which the researchers explored charcoal burning attempted suicides using an ethnographical approach. More, in most suicide attempt studies, researchers have contacted participants through hospital staff. Our study is probably the first in Hong Kong in which researchers recruited highly lethal suicide attempters through the law enforcement agency. Police officers may sometimes be seen as people in a powerful position and this might complicate the issue of recruitment. Given that the risk for further suicide and severity of distress among our targeted study participants were roughly equivalent to a clinical sample, we examined the subjective experiences of aborted suicide attempters which aimed to fill suicide research voids in Hong Kong and also the participants' study participation experiences to ensure that we did no harm to our participants.

It is recognized that bringing up memories of painful experiences, and in particular, circumstances surrounding suicidal intentions and attempts, may result in increased risk (Mishara \& Weisstub, 2005). Consistent with other sensitive research studies in the area of mental health and bereavement (Smith et al., 2010), we however found that the majority of the participants were positive about their participation in the study. The interviews did not appear to have unnecessary harmful effects on the participants but rather provided positive experiences for the participants to share their experiences and feelings with the research team. Specifically, the majority of participants' suicidality decreased during the study period, only one participant and none reported a moderate-tostrong wish to die at the one-month and three-month follow up, respectively. However, three participants were unsure whether they would make another suicide attempt at the one-month and three-month follow up. This finding also reinforces that the study participants are a group of vulnerable individuals and researching with such a group requires extra careful methodological planning and implementation.

A number of measures were taken to prevent potential harmful effects on the participants. First, the decision of those who refused to participate was respected and no further contacts were made by the PNC or the research team to minimize feelings of guilt for refusing participation. Second, different levels for consent were sought for at different stages of the study. Initially, the informed consent for further contacts by the research team was sought by the involved negotiators, consents were then sought for study participant, audio-taping, follow-up separately. We ensured that our participants were fully informed about the process of the study and had full autonomy to and not to participate at different stages of the study. Third, the timing and venue of the interview were carefully chosen to 
suit the needs of the participants.

Although the above safeguards may have prevented some harmful effects on the participants, they may not necessarily have contributed to the beneficial effects of participating in the study. While the present study did not involve any treatment component, participation in this study provided some treatment effect to the participants for a short period of time. We suspect that the interaction with the researchers and understanding that the researchers could follow-up and provide informational support may have provided an experience of interpersonal connection that might be lacking of at the time when the participants decided to attempt suicide. Moreover, both the quantitative and qualitative findings from the follow-up components suggest that the study provided the participants opportunities to discuss issues that they might not have previously shared with others. These opportunities to discuss emotional and suicide issues with professionals who were researchers with psychology training may have provided the participants to view their issues more objectively and possibly with a more problem-solving orientation towards their issues. Also, the opportunity for some participants to feel that they have contributed to future suicide prevention may also provide a positive sense to our participants.

This study has some limitations. The main one is that the acceptance rate for our study was low. During the 31 months of the data collection period, around 80 aborted attempters matched the study inclusion criteria, but only nine participated (despite 11 initially consenting to participation). This response rate is much lower than we anticipated because it was originally thought that the majority of the aborted individuals would comply with the suggestions for study participation suggested by the police officers who helped to abort their suicide attempts. We suspect that the majority of the potential participants did not want to further discuss their experiences, possibly felt shameful about their behaviors, or felt very eager to get back to their daily routines as soon as possible.

Second, there may have been some self-selection bias regarding response to the study between those who did and did not participate. We speculate that the positive effects of the interviews may not hold true for those who refused to participate in the study possibly because they believe that talking about the suicide attempt would have no, or even negative, impacts on them. Third, there has been debates about whether "interrupted suicide attempt" or "aborted suicide attempt" should only be considered as a "preparatory behaviour for suicide attempt" but not a suicide attempt per se because the attempt was "never started" (Sheehan, Giddens, \& Sheehan, 2014: p. 61).

A basic principle of ethical research and clinical practice is to minimize the risk of harm or discomfort to participants or clients. Our results show that the majority of participants reported having benefits from study participation. These findings provide useful information for researchers in designing and conducting studies into suicide and sensitive issues who must consider the needs and expectations of those who participate in the research. It is understandable that individuals who are not in the field of suicide prevention research may have con- 
cerns about the potential harmful impacts that studies on sensitive issues may bring to the potential participants. However, similar to the previous studies that have examined the research participation experiences consistently demonstrate that with strict adherence to the ethical and methodological standards and a caring attitude, therapeutic effects may be brought to the participants as this study found.

\section{Acknowledgements}

This study was funded by the General Research Fund of the Research Grants Council (HKU756211). The authors are grateful to the clinical psychologists of the Psychological Services Group of The Hong Kong Police Force for their assistance in this study. We are thankful to Prof. Paul S.F. Yip, Dr. K.W. Fu, and Dr. Gregory M. Vecchi for their comments in the study, and to all the negotiators of the PNC for their help with recruiting the participants. We are especially indebted to all participants who selflessly shared their intimate, often painful, memories of their suicide attempts with us.

\section{References}

Barber, M. E., Marzuk, P. M., Leon, A. C., \& Portera, L. (1998). Aborted Suicide Attempts: A New Classification of Suicidal Behavior. American Journal of Psychiatry, 155, 385-389. https://doi.org/10.1176/ajp.155.3.385

Brown, G. K., Jeglic, E., Henriques, G. R., \& Beck, A. T. (2006). Cognitive Therapy, Cognition, and Suicidal Behavior. In T. E. Ellis (Ed.), Cognition and Suicide: Theory, Research, and Therapy (pp. 53-74). Washington DC: American Psychological Association. https://doi.org/10.1037/11377-003

Chan, K. P., Yip, P. S., Au, J., \& Lee, D. T. (2005). Charcoal-Burning Suicide in Post-Transition Hong Kong. British Journal of Psychiatry, 186, 67-73.

https://doi.org/10.1192/bjp.186.1.67

Chang, W. C., Chen, E. S. M., Hui, C. L. M., Chan, S. K. W., Lee, E. H. M., \& Chen, E. Y. H. (2015). Prevalence and Risk Factors for Suicidal Behavior in Young People Presenting with First-Episode Psychosis in Hong Kong: A 3-Year Follow-Up Study. Social Psychiatry and Psychiatric Epidemiolgy, 50, 219-226. https://doi.org/10.1007/s00127-014-0946-5

Chen, E. Y. H., Chan, W. S. C., Wong, P. W. C., Chan, S. S. M., Chan, C. L. W., Law, Y. W. et al. (2006). Suicide in Hong Kong: A Case-Control Psychological Autopsy Study. Psychological Medicine, 36, 815-825. https://doi.org/10.1017/S0033291706007240

Cheung, Y. T. D., Wong, P. W. C., Lee, A. M., Lam, T. H., Fan, Y. S. S., \& Yip, P. S. F. (2013). Non-Suicidal Self-Injury and Suicidal Behavior: Prevalence, Co-Occurrence, and Correlates of Suicide among Adolescents in Hong Kong. Social Psychiatry and Psychiatric Epidemiolgy, 48, 1133-1144. https://doi.org/10.1007/s00127-012-0640-4

D'Zurilla, T. J., \& Nezu, A. M. (1990). Development and Preliminary Evaluation of the Social Problem-Solving Inventory. Psychological Assessment: A Journal of Consulting and Clinical Psychology, 2, 156.

Ghaffari-Nejad, A., \& Pouya, F. (2002). Aborted Suicide among Psychiatric Inpatients in Kerman. Archives of Iranian Medicine, 5, 240-243.

Goldberg, D., \& Williams, P. (1988). General Health Questionnaire (GHQ). Swindon: NFER. 
Hawton, K., Houston, K., Malmbergand, A., \& Simkin, S. (2003). Psychological Autopsy Interviews in Suicide Research: The Reactions of Informants. Archives of Suicide Research, 7, 73-82. https://doi.org/10.1080/13811110301566

Holden, R. R., \& McLeod, L. D. (2000). The Structure of the Reasons for Attempting Suicide Questionnaire (RASQ) in a Nonclinical Adult Population. Personality and Individual Differences, 29, 621-628. https://doi.org/10.1016/S0191-8869(99)00214-7

Kessler, R. C., Berglund, P., Borges, G., Nock, M., \& Wang, P. S. (2005). Trends in Suicide Ideation, Plans, Gestures, and Attempts in the United States, 1990-1992 to 2001-2003. JAMA, 293, 2487-2495. https://doi.org/10.1001/jama.293.20.2487

Lakeman, R., \& FitzGerald, M. (2009). The Ethics of Suicide Research: The Views of Ethics Committee Members. Crisis, 30, 13-19. https://doi.org/10.1027/0227-5910.30.1.13

Law, B. M., \& Shek, D. (2013). Self-Harm and Suicide Attempts among Young Chinese Adolescents in Hong Kong: Prevalence, Correlates, and Changes. Journal of Pediatric \& Adolescent Gynecology, 26, 26-32. https://doi.org/10.1016/j.jpag.2013.03.012

Lee, A., Wong, S. Y. S., Tsang, K. K., Ho, G. S. M., Wong, C. W., \& Cheng, F. (2009). Understanding Suicidality and Correlates among Chinese Secondary School Students in Hong Kong. Health Promotion International, 24, 156-165.

https://doi.org/10.1093/heapro/dap011

Linehan, M. M., Goodstein, J. L., Nielsen, S. L., \& Chiles, J. A. (1983). Reasons for Staying Alive When You Are Thinking of Killing Yourself: The Reasons for Living Inventory. Journal of Consulting and Clinical Psychology, 51, 276-286. https://doi.org/10.1037/0022-006X.51.2.276

Marzuk, P. M., Tardiff, K., Leon, A. C., Portera, L., \& Weiner, C. (1997). The Prevalence of Aborted Suicide Attempts among Psychiatric In-Patients. Acta Psychiatrica Scandinavica, 96, 492-496. https://doi.org/10.1111/j.1600-0447.1997.tb09952.x

McCubbin, M. A., McCubbin, H. I., \& Thompson, A. I. (1996). Family Problem Solving Communication (FPSC). In H. I. McCubbin, A. I. Thompson, \& M. A. McCubbin (Eds.), Family Assessment: Resiliency, Coping and Adaptation-Inventories for Research and Practice (pp. 639-688). Madison, WI: University of Wisconsin.

Michel, K., Dey, P., Stadler, K., \& Valach, L. (2004). Therapist Sensitivity towards Emotional Life-Career Issues and the Working Alliance with Suicide Attempters. Archives of Suicide Research, 8, 203-213. https://doi.org/10.1080/13811110490436792

Mishara, B. L., \& Weisstub, D. N. (2005). Ethical and Legal Issues in Suicide Research. International Journal of Law and Psychiatry, 28, 23-41. https://doi.org/10.1016/j.ijlp.2004.12.006

Moscicki, E. K., Muehrer, P., \& Potter, L. B. (1995). Introduction to Supplemental Issue: Research Issues in Suicide and Sexual Orientation. Suicide and Life Threatening Behavior, 25, 1-3.

Nock, M. K., Borges, G., Bromet, E. J., Cha, C. B., Kessler, R. C., \& Lee, S. (2008). Suicide and Suicidal Behavior. Epidemiologic Reviews, 30, 133-154.

https://doi.org/10.1093/epirev/mxn002

Owens, D., Horrocks, J., \& House, A. (2002). Fatal and Non-Fatal Repetition of Self-Harm. Systematic Review. British Journal of Psychiatry, 181, 193-199. https://doi.org/10.1192/bjp.181.3.193

Posner, K., Brent, D., Lucas, C., Gould, M., Stanley, B., Brown, G., Mann, J. et al. (2008). Columbia-Suicide Severity Rating Scale (C-SSRS). http://cssrs.columbia.edu/wp-content/uploads/C-SSRS1-14-09-SinceLastVisit.pdf

Posner, K., Brown, G. K., Stanley, B., Brent, D. A., Yershova, K. V., Oquendo, M. A., Mann, J. J. et al. (2011). The Columbia-Suicide Severity Rating Scale: Initial Validity 
and Internal Consistency Findings from Three Multisite Studies with Adolescents and Adults. American Journal of Psychiatry, 168, 1266-1277. https://doi.org/10.1176/appi.ajp.2011.10111704

Sheehan, D. V., Giddens, J. M., \& Sheehan, K. H. (2014). Current Assessment and Classification of Suicidal Phenomena Using the FDA 2012 Draft Guidance Document on Suicide Assessment: A Critical Review. Innovations in Clinical Neuroscience, 11, 54-65.

Silverman, M. M., Berman, A. L., Sanddal, N. D., O’Carroll, P. W., \& Joiner, T. E. (2007). Rebuilding the Tower of Babel: A Revised Nomenclature for the Study of Suicide and Suicidal Behaviors. Part 2: Suicide-Related Ideations, Communications, and Behaviors. Suicide and Life-Threatening Behavior, 37, 264-277. https://doi.org/10.1521/suli.2007.37.3.264

Smith, P., Poindexter, E., \& Cukrowicz, K. (2010). The Effect of Participating in Suicide Research: Does Participating in a Research Protocol on Suicide and Psychiatric Symptoms Increase Suicide Ideation and Attempts? Suicide and Life Threatening Behavior, 40, 535-543. https://doi.org/10.1521/suli.2010.40.6.535

Steger, M. F., Frazier, P., Oishi, S., \& Kaler, M. (2006). The Meaning in Life Questionnaire: Assessing the Presence of and Search for Meaning in Life. Journal of Counseling Psychology, 53, 80-93. https://doi.org/10.1037/0022-0167.53.1.80

The Division of Psychiatry Products in the Center for Drug Evaluation and Research (CDER) at the Food and Drug Administration (2012). Guidance for Industry Suicidal Ideation and Behavior: Prospective Assessment of Occurrence in Clinical Trials. http://www.fda.gov/downloads/Drugs/.../Guidances/UCM225130.pdf

Traskman-Bendz, L., \& Mann, J. J. (2000). Biological Aspects of Suicidal Behaviour. In K. Hawton, \& K. van Heeringen (Eds.), The International Handbook of Suicide and Attempted Suicide (pp. 65-77). Hoboken, NJ: John Wiley \& Sons. https://doi.org/10.1002/9780470698976.ch4

Van Heeringen, K., Hawton, K., \& Williams, J. M. G. (2000). Pathways to Suicide: An Integrative Approach. In K. Hawton, \& K. van Heeringen (Eds.), The International Handbook of Suicide and Attempted Suicide (pp. 223-234). Hoboken, NJ: John Wiley \& Sons. https://doi.org/10.1002/9780470698976.ch14

Wong, J. P. S., Stewart, S. M., \& Lam, T. H. (2007). Risk Factors Associated with Suicide Attempts and Other Self-Injury among Hong Kong Adolescents. Suicide and Life Threatening Behavior, 37, 453-466. https://doi.org/10.1521/suli.2007.37.4.453

Wong, P. W. C., Caine, E. D., Lee, C. K. M., Beautrais, A., \& Yip, P. S. F. (2014). Suicides by Jumping from a Height in Hong Kong: A Review of Coroner Court Files. Social Psychiatry and Psychiatric Epidemiolgy, 49, 211-219. https://doi.org/10.1007/s00127-013-0743-6

Wong, P. W., Chan, W. S., Beh, P. S., Yau, F. W., Yip, P. S., \& Hawton, K. (2010). Research Participation Experiences of Informants of Suicide and Control Cases: Taken from a Case-Control Psychological Autopsy Study of People Who Died by Suicide. Crisis, 31, 238-246. https://doi.org/10.1027/0227-5910/a000025

Wong, P. W., Chan, W. S., Chen, E. Y., Chan, S. S., Law, Y. W., \& Yip, P. S. (2008). Suicide among Adults Aged 30-49: A Psychological Autopsy Study in Hong Kong. BMC Public Health, 8, 147. https://doi.org/10.1186/1471-2458-8-147

Yim, P. H. W., Yip, P. S. F., Li, R. H. Y., Dunn, E. L. W., Yeung, W. S., \& Miao, Y. K. (2004). Suicide after Discharge from Psychiatric Inpatient Care: A Case-Control Study in Hong Kong. Australian and New Zealand Journal of Psychiatry, 38, 65-72. https://doi.org/10.1111/j.1440-1614.2004.01299.x

Zhang, J., \& Jia, C. X. (2007). Validating a Short Version of the Suicide Intent Scale in China. Omega: Journal of Death and Dying, 55, 255-265. 
https://doi.org/10.2190/om.55.4.a

Zimet, G. D., Powell, S. S., Farley, G. K., Werkman, S., \& Berkoff, K. A. (1990). Psychometric Characteristics of the Multidimensional Scale of Perceived Social Support. Journal of Personality Assessment, 55, 610-617. https://doi.org/10.1080/00223891.1990.9674095

Submit or recommend next manuscript to SCIRP and we will provide best service for you:

Accepting pre-submission inquiries through Email, Facebook, LinkedIn, Twitter, etc. A wide selection of journals (inclusive of 9 subjects, more than 200 journals)

Providing 24-hour high-quality service

User-friendly online submission system

Fair and swift peer-review system

Efficient typesetting and proofreading procedure

Display of the result of downloads and visits, as well as the number of cited articles Maximum dissemination of your research work

Submit your manuscript at: http://papersubmission.scirp.org/

Or contact psych@scirp.org 